Research Article

\title{
Constitutive Model of Swelling Gypsum Rock
}

\author{
Chongbang Xu, ${ }^{1,2,3}$ Xiaojing Gao $\mathbb{D}^{1,2,3}$ Kaishun Zhang, ${ }^{4}$ Zhiguo Liu, ${ }^{4}$ and Fan Zhao ${ }^{4}$ \\ ${ }^{1}$ Bridge and Tunnel Research Center, Research Institute of Highway Ministry of Transport, Beijing 100088, China \\ ${ }^{2}$ National Engineering Laboratory of Bridge Structure Safety Technology, Beijing 100088, China \\ ${ }^{3}$ Research Institute of Highway Ministry of Transport Research and Development Center of Transport Industry of Technologies \\ and Equipments for Intelligent Design, Construction and Maintenance of Underwater Tunnel, Ministry of Transport, \\ Beijing 100088, China \\ ${ }^{4}$ The 5th Engineering Co., Ltd. of China Railway 11th Bureau Group, Chongqing 400037, China
}

Correspondence should be addressed to Xiaojing Gao; xiaojing.gao1990@foxmail.com

Received 3 August 2020; Revised 19 September 2020; Accepted 22 September 2020; Published 8 October 2020

Academic Editor: Zhi Cheng Tan

Copyright $\odot 2020$ Chongbang Xu et al. This is an open access article distributed under the Creative Commons Attribution License, which permits unrestricted use, distribution, and reproduction in any medium, provided the original work is properly cited.

\begin{abstract}
Swelling of soft rock, such as gypsum rock, is one of the major threats in tunnel engineering, causing structure damages such as floor heave and inward movement of sidewalls during construction and operation. It is of practical significance to study the swelling mechanical behavior of such rocks by tests. Swelling strain tests and swelling stress tests were performed by swelling test apparatus to study the variation of swelling strain with time and the swelling stress-strain relationship for gypsum rock samples, respectively. Three stages of the swelling strain on the time-strain curve of gypsum rock samples were noticed, which are defined as rapid swelling stage, slow swelling stage, and steady stage. And it was further found that the swelling strain caused in the slow swelling stage is of $76 \%$ of the total swelling strain. A constitutive model is proposed to describe the stress-strain relationship in swelling considering the swelling deformation and swelling pressure. The proposed model was verified using test data, which shows good agreements in describing the relationship between swelling strain and swelling stress, also in the conditions of maximum swelling strain and maximum swelling stress under lateral restraint situations.
\end{abstract}

\section{Introduction}

A growing number of road and railway tunnels in complex geological conditions are being constructed with the implementation of the China Western Development Strategy, which are considered as the important structure of transportation infrastructure. There are large amounts of formations containing swelling rocks, such as gypsum and anhydrite, widespread in Western China [1]. The swelling of rocks causes severe problems in tunnel engineering, such as floor heave, inward movement of sidewalls, and destruction of tunnel linings [2]. The swelling behavior of rocks was usually investigated in laboratory condition. Most laboratory experiments or theoretical analyses on the swelling characteristics of a shield tunnel in swelling rock are under certain hypotheses which have not been verified in actual situation. Currently, it is impossible to predict the swelling behavior of an actual geotechnical project due to our limited knowledge of the processes involved in the swelling of rock and of the geological, mineralogical, chemical, hydraulic, and mechanical controls of the swelling [3]. Historically, swelling rock studies have been largely concentrated on swelling mechanism $[4,5]$ and factors affecting the swelling [6-9]. Several swelling tests are available on the variation of swelling deformation $[10,11]$ and swelling constitutive relationship [12-19], which help geotechnical engineers to understand the swelling behavior of rock well.

The swelling of gypsum rocks is a major threat in tunnel engineering, causing serious damage to tunnels and producing high additional costs during tunnel construction and operation. Steiner et al. [20] proposed brittle failure of the anhydrite rock after tunnel excavation to be a major process leading to rock swelling. Liu et al. [21] studied the swelling characteristics of gypsum rock and obtained the relationships between swelling stress and water absorption also initial dry density. Gypsum rocks immersed by fresh water 
within different times were investigated according to softening tests by Ren et al. [22]. The variations of uniaxial compressive strength, shear strength, elastic modulus, and Poisson's ratio of gypsum rocks with increasing immersion time were analyzed. The factors influencing the swelling characteristics of swelling rock were investigated [23, 24]; it was found that the density and the initial moisture content of rock significantly affected the swelling characteristics of rock.

Huder and Amberg [25] conducted experiments to investigate the swelling characteristics of swelling rock; a relation between normal stress and normal swelling strain was developed. Based on the experimental results of Huder and Amberg [25], Grob [26] proposed a mathematical model for relating final swelling strain to stress, the swelling strain decreases with logarithm of stress, and maximum swelling occurs when there is a minimum normal stress acting on the specimen. The one-dimensional mathematical model of Grob was expanded to three-dimensional constitutive law by Wittke-Gattemann and Wittke [27]. Einstein [28] examined the available swelling models in the literature and concluded that, although the swelling deformation due to chemical changes may be adequately predicted using available models, but time-dependent swelling models need to be developed from a fundamental knowledge of swelling mechanism. Miao et al. [29] proposed the humidity field theory which provided theories foundation for constitutive model of swelling rock. Based on the humidity stress field theory, Chen et al. [30] carried out swelling tests on anhydrite rock mass and proposed a time-dependent swelling constitutive model, and Yu et al. [31] proposed a physical equation to describe a tunnel's mechanical responses in swelling rock. Most of the swelling constitutive models were developed based on the swelling tests and theoretical analysis, while the condition of rock tested in swelling tests is different from that in actual situation. Up to now, no common opinion is offered about the applicability of constitutive laws with which the swelling phenomena of rocks can be described. A swelling model considering the swelling behavior in engineering is needed to solve actual problems.

Swelling characteristics of gypsum rock varies as diagenesis environment and occurrence varies. Swelling strain tests were conducted to investigate the variation of swelling strain with time for gypsum rock. Based on the results of swelling strain test, swelling stress tests under conditions of controlling the swelling strain were carried out to study the swelling stress-strain relationship for gypsum rock. A formula describing the swelling potential of rock was proposed by introducing virtual swelling stress and virtual swelling strain. A swelling constitutive model was developed and verified using three sets of experimental data from the present research and literature.

\section{Swelling Test}

2.1. Materials. The gypsum rock blocks, taken from the surrounding rock of Dugongling tunnel in Shanxi Province, China, were used to prepare the samples of swelling tests. The gypsum rock blocks were transported to the laboratory and processed into the samples with $50 \mathrm{~mm}$ diameter and $36 \mathrm{~mm}$ height. The powder of natural gypsum rock passing sieve number 500 was used to test the mineralogical composition of gypsum rock by D8-ADVANCE type X-ray diffractometer. A typical XRD pattern is shown in Figure 1. Results of XRD test in Table 1 show that the gypsum rock is mainly composed of dihydrate gypsum, anhydrite, and quartz. The density and natural moisture content were tested according to the Chinese Soil Test Standard SL237. The measured density of gypsum rock ranged from $2240 \mathrm{~kg} \cdot \mathrm{m}^{-3}$ to $2370 \mathrm{~kg} \cdot \mathrm{m}^{-3}$. The natural moisture content of gypsum rock was $0.12 \%$.

2.2. Test Procedure. The samples of gypsum rock were dried under $220^{\circ} \mathrm{C}$ condition for 48 hours using a drying oven. The dried samples were put in a sealed bag for sealing. Lateral restraint swelling equipment SCY-2 shown in Figure 2 was used to conduct the swelling strain tests and swelling stress tests. The primary components of SCY-2 are a water container, a rigid snug-fitting restraint ring, dial gage, and a loading device.

The swelling strain is the change in height of the sample divided by the initial height of the sample immersed in water and expressed in percentage. The procedure of the swelling strain test is as follows:

(1) Apply some Vaseline lotion around the inside of a rigid snug-fitting ring and place the rock sample in the ring. The ring containing the sample is placed in the water container.

(2) Place the porous disks at the top and bottom of the sample.

(3) Assemble the water container and dial gage. Check the dial gage and make sure it is precise. The top of the sample is not subjected to any axial load.

(4) Add enough water into the water container so that swelling can start. The water level should be higher than the surface of upper porous disk.

(5) Record the axial swelling movement of the sample as a function of time using the dial gage. The swelling test is finished when the axial swelling movement reaches an equilibrium value, that strain is the maximum swelling strain $\varepsilon_{0}$.

Swelling stress is the ratio of the force which can inhibit the swelling strain caused by the water seeped into the sample to the sectional area of the sample. Swelling stress tests were performed to measure the swelling stress using balanced pressure method according to the Chinese Soil Test Standard SL237. Four sets of swelling stress tests were conducted to measure the swelling stress by controlling the axial strain equal to $0,20,40$, and 60 percent of the maximum swelling strain measured in the swelling strain test. The procedure of the swelling stress tests is as follows:

(1) Apply some Vaseline lotion around the inside of a rigid snug-fitting ring and place the rock sample in the ring. The ring containing the sample is placed in the water container. 


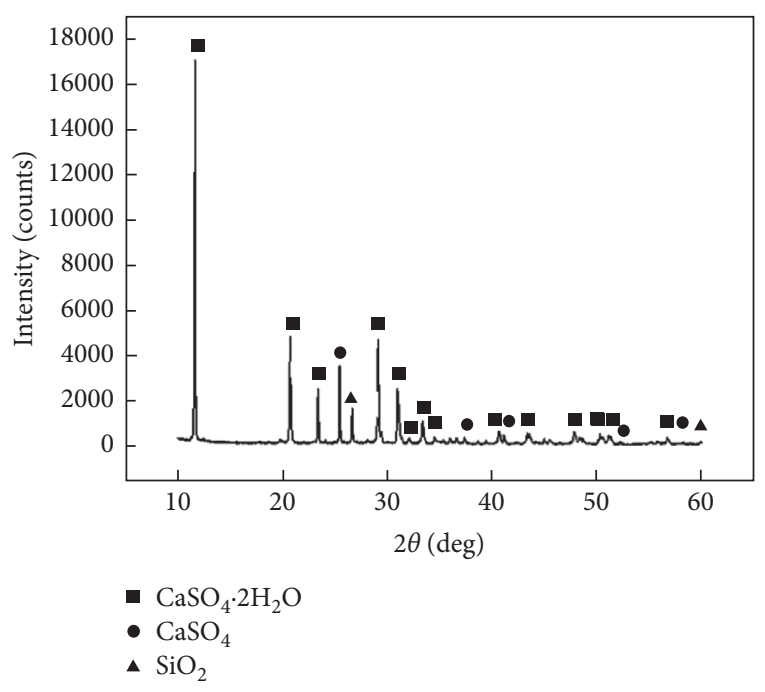

FIGURE 1: XRD pattern of gypsum rock.

TABle 1: Mineralogical composition of gypsum rock.

\begin{tabular}{lc}
\hline Mineral & Composition of mineral (\%) \\
\hline Dihydrate gypsum $\left(\mathrm{CaSO}_{4} \cdot 2 \mathrm{H}_{2} \mathrm{O}\right)$ & 75 \\
Anhydrite $\left(\mathrm{CaSO}_{4}\right)$ & 20 \\
Quartz $\left(\mathrm{SiO}_{2}\right)$ & 5
\end{tabular}

(2) Place the porous disks at the top and bottom of the sample. The pressure sensor is placed at the top of the upper porous disk.

(3) Assemble the water container, dial gage, and loading device. Check the dial gage and make sure it is precise.

(4) Add enough water into the water container so that swelling can start. The water level should be higher than the surface of upper porous disk.

(5) Record the swelling movement by the dial gage. Apply axial load to maintain the swelling movement constant when the swelling strain reaches the required value $(0 \%, 20 \%, 40 \%$, and $60 \%$ maximum swelling strain). The swelling test is finished when the axial swelling stress reaches an equilibrium value, that stress is the swelling stress under the induced swelling strain condition.

The swelling strain is maintained as $0 \%$ maximum swelling strain during the swelling stress tests; when the axial stress reaches an equilibrium value, that stress is the maximum swelling stress $\sigma_{0}$.

\section{Results of the Swelling Test}

3.1. Swelling Strain. Figure 3 presents a plot showing the variation of swelling strain with time. It can be seen from Figure 3(a) that the procedure of swelling for gypsum rock lasted for about 300 minutes. The maximum swelling strain was equal to $4.397 \%$. Regression works were conducted based on maximizing the coefficient of determination $R^{2}$.
The regression result shows that there is a positive exponential relationship between swelling strain and time:

$$
\varepsilon=5.167 \exp \left(-\frac{36.2}{t}\right)
$$

where $\varepsilon$ is the swelling stain and $t$ is the swelling time.

The slope of the dash curve (Figure 3(a)) is the derivative of equation (1), which increases first and then decreases with increasing the time as shown in Figure 4. A point of the dash curve represents the maximum derivative of equation (1), which corresponds to the swelling time of 18.1 minutes. The swelling strain of the point corresponding to the swelling time of 18.1 minutes was about $0.56 \%$; this point on the swelling strain versus time curve was named as A. Once the swelling time exceeds 18.1 minutes, the slope of dash curve shows a decreasing trend as the time increases. The data point at which the swelling strain is $90 \%$ of the maximum swelling strain was selected as point B shown in Figure 3(a). The data point on the swelling strain versus time curve corresponding to the final time was named as point $\mathrm{C}$. According to the three points, $\mathrm{A}, \mathrm{B}$, and $\mathrm{C}$, the swelling strain versus time curve shown in Figure 3(a) can be divided into three parts: rapid swelling stage (path $0 \mathrm{~A}$ ), slow swelling stage (path $\mathrm{AB}$ ), and stable stage (path BC).

The rapid swelling stage lasted for about 18 minutes. For rapid swelling stage, the swelling deformation was too small to be measured at the first three minutes. The voids in the gypsum rock were filled with the swelling deformations of rock that occurred at the first three minutes. As the filling of swelling deformations in the rock voids, the increment of swelling strain increases rapidly at the rapid swelling stage (Figure 3(b)). The slow swelling stage lasted for about 115 minutes, and the swelling strain $(\varepsilon)$ was $3.96 \%$. The swelling strain generated in the slow swelling stage is $76 \%$ of the maximum swelling strain. The path BC in Figure 3(a) shows that the increment of swelling deformation gradually tends to zero with an increase in time, and the swelling strain ends up reaching an equilibrium value called the maximum swelling strain $\varepsilon_{0}$.

3.2. Swelling Stress. Results of swelling stress under conditions of controlling the swelling strain of $0 \%, 20 \%, 40 \%$, and $60 \%$ maximum swelling strain are shown in Table 2. The measured maximum swelling stress was $3340 \mathrm{kPa}$ for the gypsum rock tested in the present research.

\section{Swelling Constitutive Model}

4.1. Development of the Swelling Constitutive Model. For a certain type of swelling rock, the swelling characteristics are closely related to the intrinsic rock property without considering the environmental factors. The swelling behavior of rock is externally expressed in the form of swelling pressure and swelling deformation which are parameterized by swelling stress and swelling strain, respectively [32]. Different from the rock stress-strain relationship measured under external load, there is a negative correlation between 


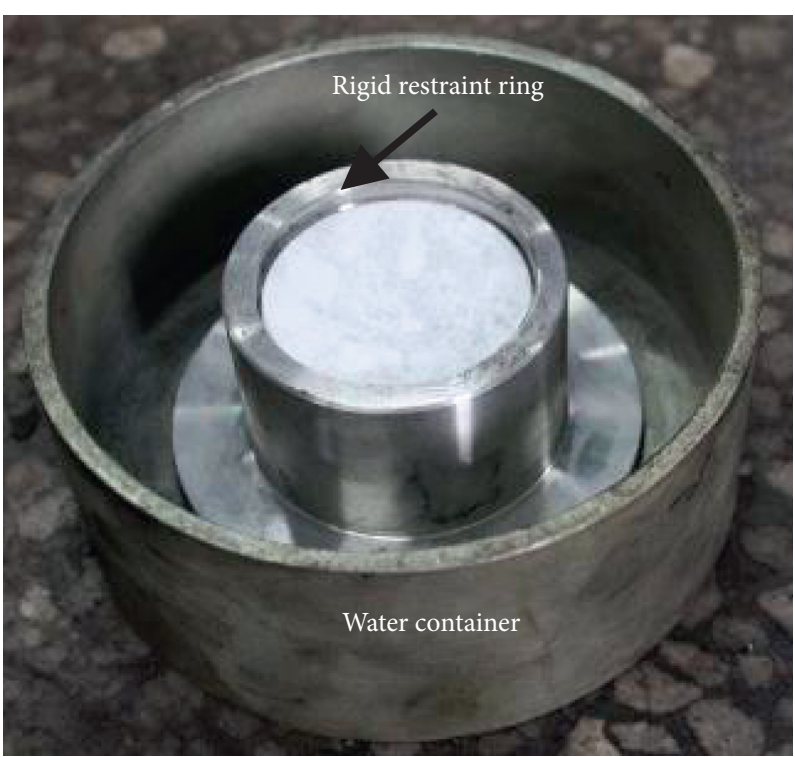

(a)

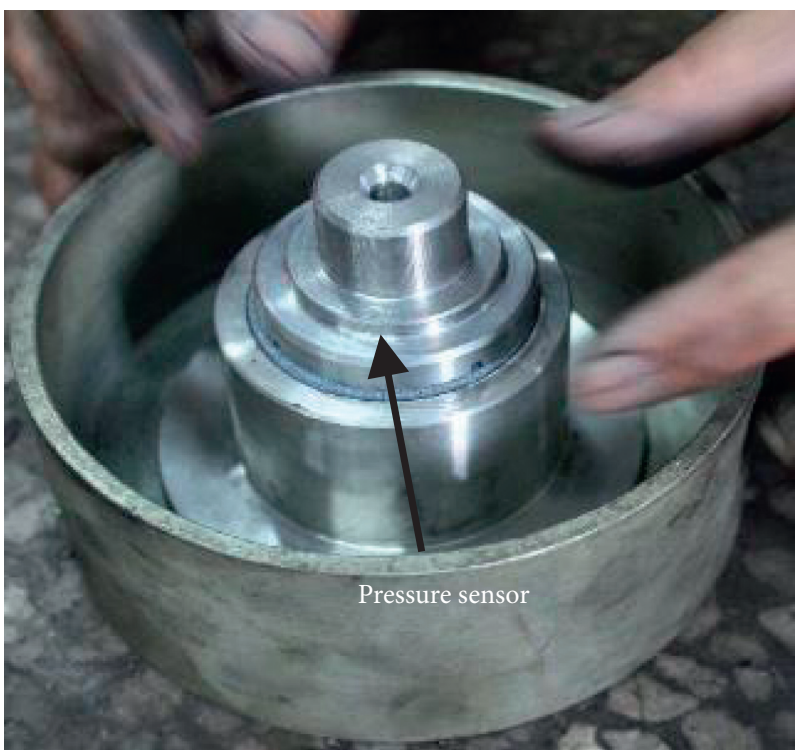

(c)

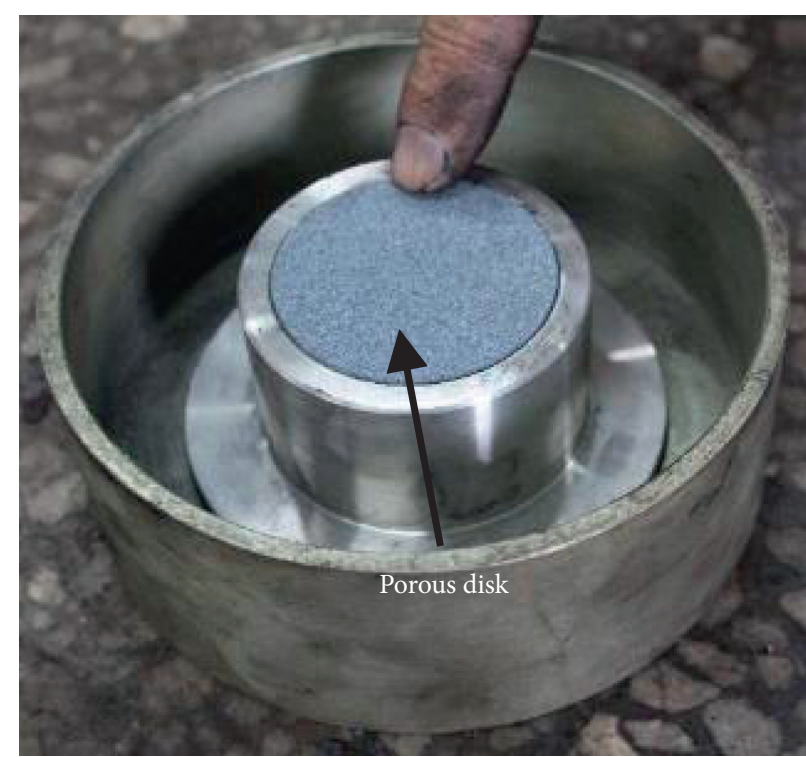

(b)

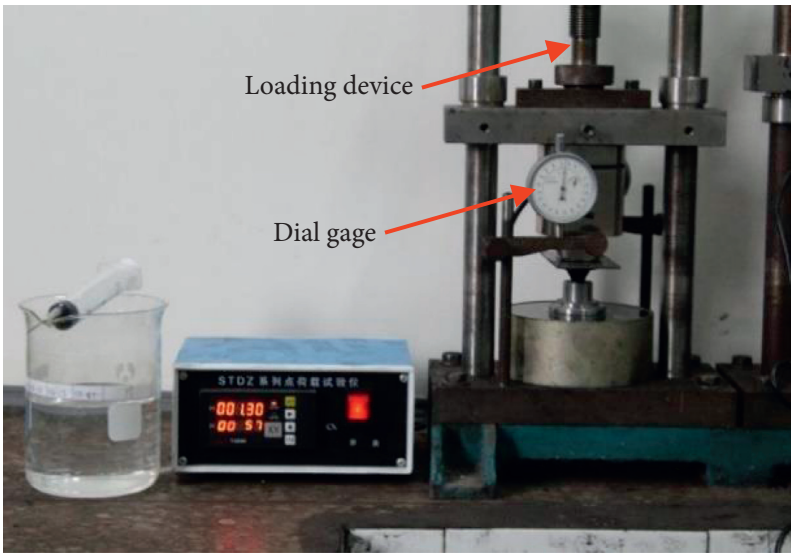

(d)

Figure 2: Swelling test apparatus.

swelling stress and swelling strain when considering the swelling behavior of rock. The swelling stress shows a decreasing trend with an increase in swelling strain. For the condition of maximum swelling stress, the swelling stress is the largest and the swelling strain is 0 . For the condition of maximum swelling strain, the swelling stress is 0 and the swelling strain is the largest.

Assumptions were made to propose a swelling constitutive model considering the swelling behavior of rock as follows:

(1) The swelling potential $Q_{s}$ of a certain swelling rock only depends on its intrinsic property, which can be expressed by swelling stress or swelling strain.
(2) Swelling pressure and swelling deformation are the external form of swelling behavior. The swelling potential can be decomposed into swelling potential expressed by swelling pressure $Q_{\sigma}$ and swelling potential expressed by swelling deformation $Q_{\varepsilon}$, which can be parameterized by swelling stress or swelling strain. The expression of swelling potential of rock is as follows:

$$
Q_{s}=Q_{\sigma}+Q_{\varepsilon} .
$$

(3) The virtual swelling moduli $E_{p \varepsilon}$ and $E_{p \sigma}$ were introduced into the expressions of virtual swelling stress $\left(\sigma_{\varepsilon}\right.$, $\mathrm{kPa}$ ) and virtual swelling strain $\left(\varepsilon_{\sigma}\right)$, respectively: 


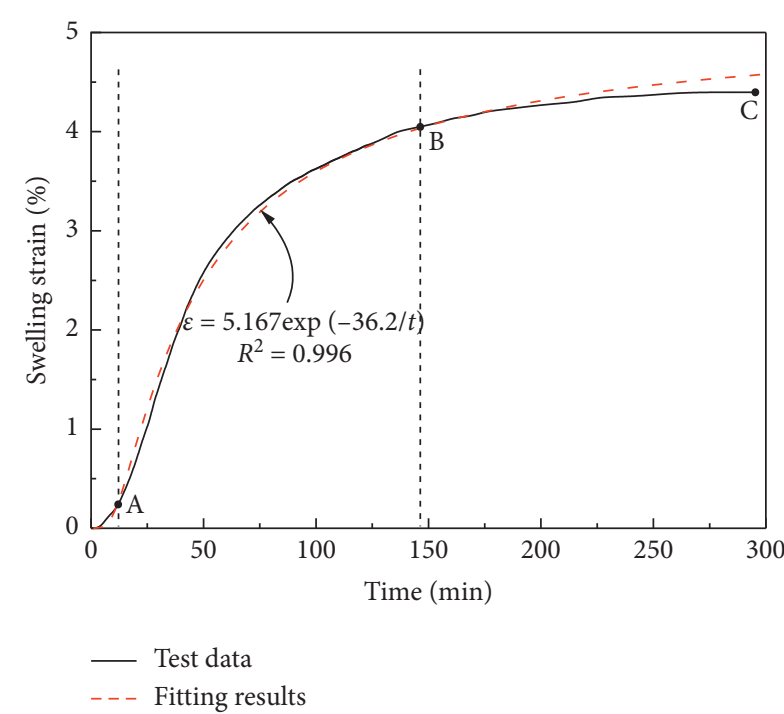

(a)

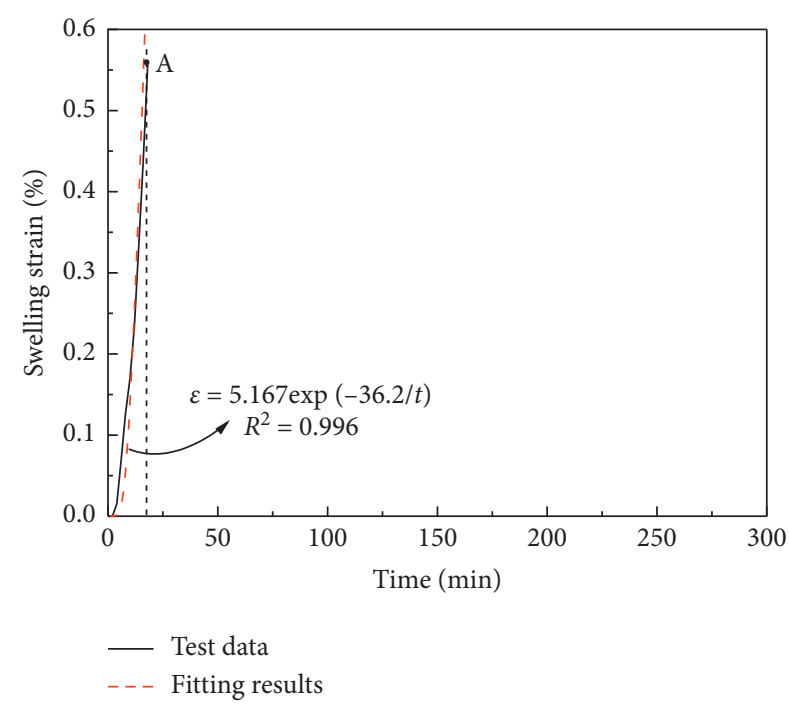

(b)

FIGURE 3: Variation of swelling strain with time.

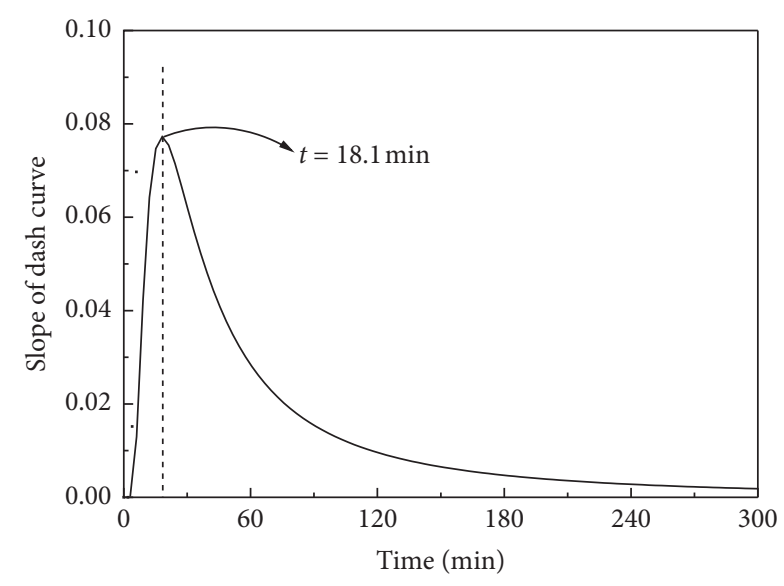

FIgURE 4: Variation of slope of dash curve with time.

TABLE 2: Results of swelling stress test.

\begin{tabular}{lccc}
\hline$p_{s}(\%)$ & $s(\mathrm{~mm})$ & $\varepsilon(\%)$ & $\sigma(\mathrm{kPa})$ \\
\hline 0 & 0.000 & 0.000 & 3340 \\
20 & 0.317 & 0.879 & 2720 \\
40 & 0.633 & 1.759 & 1970 \\
60 & 0.950 & 2.638 & 1120 \\
\hline
\end{tabular}

$$
\begin{aligned}
& \sigma_{\varepsilon}=f\left(\varepsilon, E_{P \varepsilon}\right), \\
& \varepsilon_{\sigma}=f\left(\sigma, E_{P \sigma}\right),
\end{aligned}
$$

where $\varepsilon$ is the actual swelling strain, and $\sigma(\mathrm{kPa})$ is the actual swelling stress.

In this research, the swelling potential was parameterized by swelling stress. The swelling stress-strain relationship was analyzed using the experimental data from the swelling tests under lateral restraint condition. It is assumed that there are linear relationships between swelling stress and swelling strain, so that equations (3) and (4) become

$$
\begin{gathered}
\sigma_{\varepsilon}=E_{P \varepsilon} \varepsilon, \\
\varepsilon_{\sigma}=\frac{\sigma}{E_{P \sigma}} .
\end{gathered}
$$

$Q_{\sigma}$ and $Q_{\varepsilon}$ are expressed using the actual swelling stress and virtual swelling stress, respectively, which can be written as follows:

$$
\begin{gathered}
Q_{\sigma}=\sigma, \\
Q_{\varepsilon}=E_{P \varepsilon} \varepsilon .
\end{gathered}
$$

Substituting equations (6) and (7) into (2) leads to

$$
Q_{s}=\sigma+E_{p \varepsilon} \varepsilon \text {. }
$$

Equation (8) is a general formula, which can represent the swelling behavior of a certain type of swelling rock under different conditions. The swelling rock under the condition of maximum swelling stress and maximum swelling strain are the two special conditions in equation (8).

The maximum swelling stress $\sigma_{0}$ can be measured using the swelling stress test under lateral restraint condition. The axial swelling strain of a sample immersed in water is kept 0 by applying axial load; the maximum loading stress is the maximum swelling stress. For the condition of maximum swelling stress, equation (8) can be expressed as follows:

$$
Q_{s}=\sigma_{0} \text {. }
$$

The maximum swelling strain $\varepsilon_{0}$ is the final swelling strain measured from the swelling strain test under lateral restraint condition. The top of the rock sample is not subjected to any axial load. For the condition of maximum swelling strain, equation (8) can be written as 


$$
Q_{s}=E_{p \varepsilon} \varepsilon_{0} .
$$

For a certain swelling rock, the swelling potential $Q_{s}$ is constant under different swelling conditions. Equations (9) and (10) can be rewritten as

$$
E_{p \varepsilon}=\frac{\sigma_{0}}{\varepsilon_{0}} .
$$

Substituting equations (9) and (11) into (8), one can derive

$$
\sigma_{0}=\sigma+\frac{\sigma_{0}}{\varepsilon_{0}} \varepsilon
$$

Equation (12) can be rewritten as

$$
\varepsilon=\varepsilon_{0}\left(1-\frac{\sigma}{\sigma_{0}}\right)
$$

Equation (13) is the swelling constitutive model developed in present research.

4.2. Test of the Proposed Model. The proposed constitutive model (equation (13)) was tested using the experimental data presented in this paper and the collected data from Chang et al. [14] and Liu et al. [11]. In the present research, the measured maximum swelling stress $\left(\sigma_{0}\right)$ and maximum swelling strain $\left(\varepsilon_{0}\right)$ were $3340 \mathrm{kPa}$ and $4.397 \%$, respectively. Figure 5 compares the measured swelling stress and those calculated using equation (13) for gypsum rock. Equation (13) has a $R^{2}$ of 0.993 for the data in Table 2, which indicates that the proposed swelling constitutive model reproduces well the swelling stressstrain relationship for gypsum rock tested in the present research.

The experiments of Chang et al. [14] were conducted on red sandstone taken from Zhuzhou in China to measure the swelling strain by loading the specimen under one certain axial pressure in the condition of lateral restraint. The pressure acted on the rock sample can be considered as the swelling stress. The measured swelling strain is shown in Table 3 . The maximum swelling stress $\left(\sigma_{0}\right)$ and maximum swelling strain $\left(\varepsilon_{0}\right)$ were not measured in the experiments of Chang et al. [14]. Linear interpolation method was used to determine $\sigma_{0}$ and $\varepsilon_{0}$ according to two sets of data points on line No. 1 and on another line shown in Table 3. For example, the $\sigma_{0}$ on line No. 2 was calculated using the data of $\sigma$ and $\varepsilon$ on line No. 1 and on line 2 , the same as $\varepsilon_{0}$. The average of the calculated $\sigma_{0}$ was considered as the parameter of the proposed formula, the same as $\varepsilon_{0}$. The maximum swelling stress $\left(\sigma_{0}\right)$ and maximum swelling strain $\left(\varepsilon_{0}\right)$ of red sandstone were estimated as $163.10 \mathrm{kPa}$ and $0.923 \%$, respectively.

Figure 6 compares the predictions and measurements for the red sandstone tested by Chang et al. [14]. The $R^{2}$ between the measured swelling stress and the calculated swelling stress is 0.975 , which reveals that the proposed swelling model can be used to describe the swelling stress-strain relationship for red sandstone.

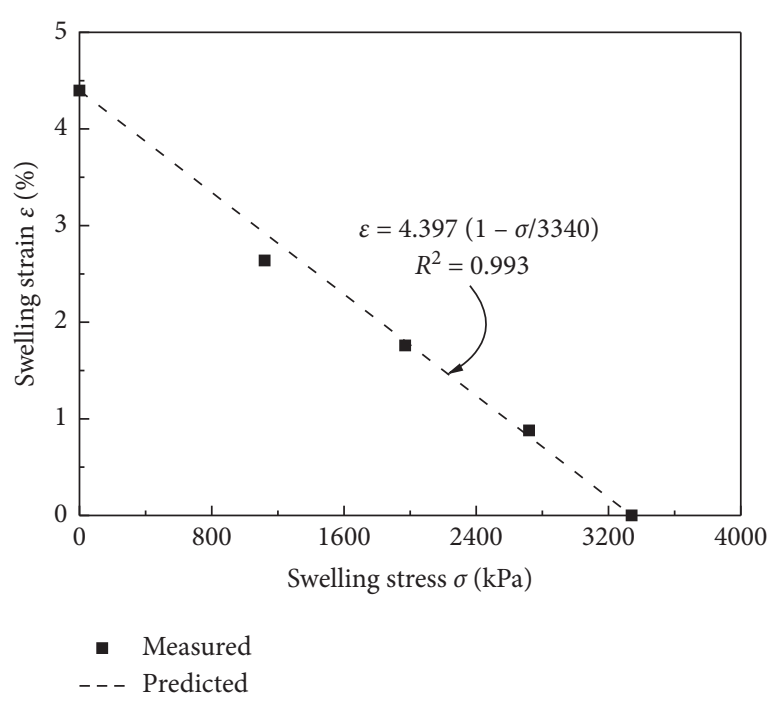

FIgURE 5: Comparison of measured and calculated swelling stress for gypsum rock.

TABle 3: Experimental data of Chang et al. [14].

\begin{tabular}{lcccc}
\hline No. & $\sigma(\mathrm{kPa})$ & $\varepsilon(\%)$ & $\sigma_{0}(\mathrm{kPa})$ & $\varepsilon_{0}(\%)$ \\
\hline 1 & 38.86 & 0.7019 & - & - \\
2 & 48.58 & 0.6462 & 161.34 & 0.924 \\
3 & 68.09 & 0.5162 & 149.34 & 0.949 \\
4 & 107.04 & 0.3086 & 160.54 & 0.926 \\
5 & 146.05 & 0.1733 & 181.19 & 0.894 \\
\hline
\end{tabular}

Liu et al. [11] studied the swelling properties of remolded rock in Middle Route Project of South-toNorth Water Diversion using swelling strain tests and swelling stress tests. The swelling stress of rock was measured by remaining the swelling strain constant at $0 \%, 1 \%, 2 \%$, and $3 \%$ for swelling rock with different initial water content $w, 14 \%, 17 \%$, and $20 \%$ (Table 4). The maximum swelling stress of rock with initial water content of $14 \%, 17 \%$, and $20 \%$ was 1044,1014 , and $924 \mathrm{kPa}$, respectively. The maximum swelling strain was not measured by Liu et al. [11], which was calculated based on the experimental data shown in Table 4 using linear interpolation method mentioned in previous paragraph. The calculated maximum swelling strain for rock with initial water content of $14 \%, 17 \%$, and $20 \%$ was $6.93 \%, 6.72 \%$, and $6.67 \%$, respectively. The variation of calculated maximum swelling strain with initial water content indicates that an increase in the initial water content leads to a decrease in swelling strain in the same external load state. This is consistent with the finding of Wang et al. [23].

Figure 7 shows the calculated and measured swelling strain for swelling rock tested by Liu et al. [11]. The $R^{2}$ between the measured and calculated swelling strain for the three sets of tests is larger than 0.95 , which reveals that the proposed swelling constitutive model performs well in describing the swelling stress-strain relationship for remolded swelling rock. 


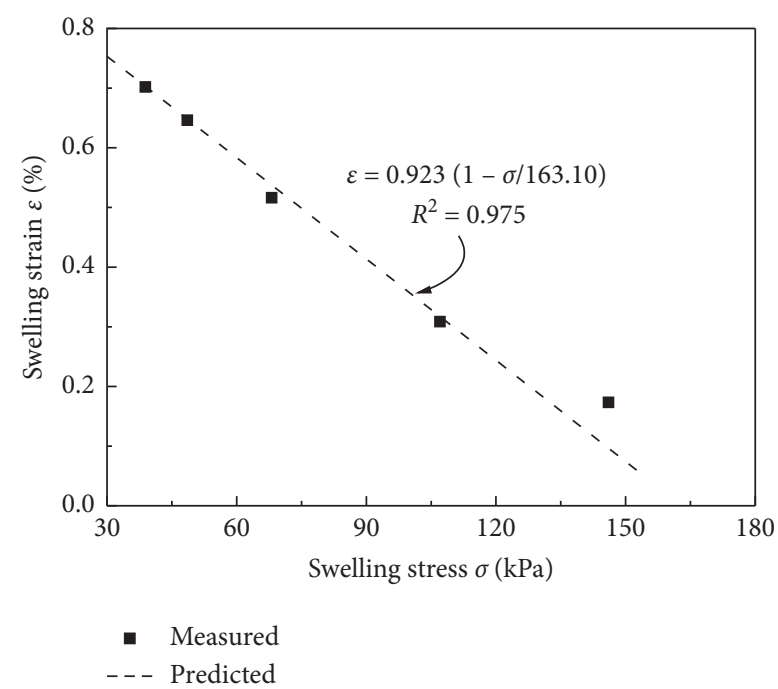

FIgURE 6: Comparison of measured and calculated swelling test data for red sandstone of Chang et al. [14].

TAble 4: Experimental data of Liu et al. [11].

\begin{tabular}{lcccc}
\hline No. & $\varepsilon(\%)$ & & & \\
& & $w=14 \%$ & $w P a$ & \\
& & 1044 & 1014 & $w=20 \%$ \\
\hline 1 & 0 & 886 & 846 & 924 \\
2 & 1 & 740 & 711 & 658 \\
3 & 2 & 616 & 604 & 560 \\
4 & 3 & &
\end{tabular}

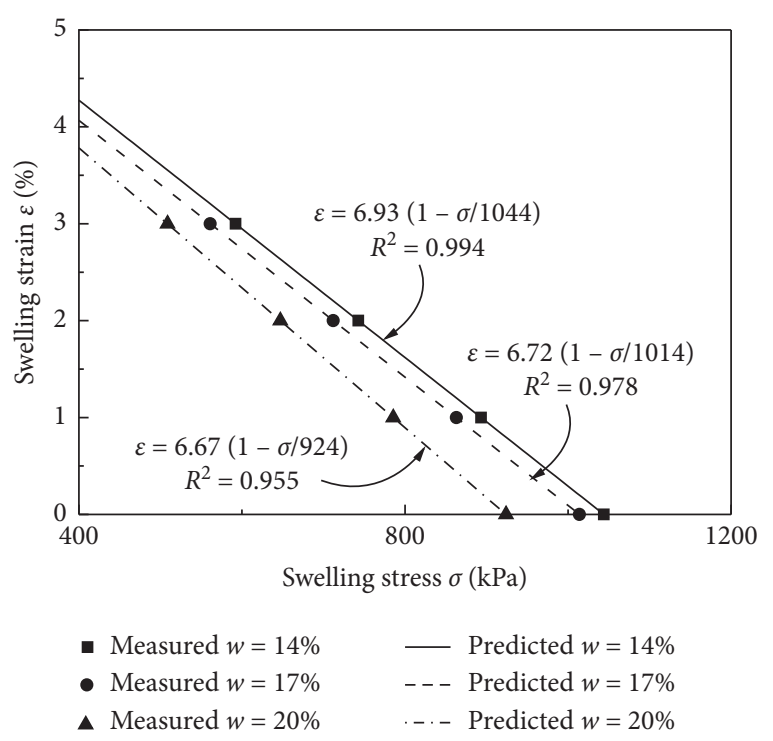

FIgURE 7: Comparison of measured and calculated swelling test data for swelling rock of Liu et al. [11].

\section{Discussion}

A constitutive model (equation (14)) proposed based on the experimental results of Huder and Amberg [25] was widely used in describing the swelling stress-strain relationship. The difference between the proposed model in present research and the Huder-Amberg model was discussed. The Huder-Amberg model is written as follows:

$$
\varepsilon=K\left(1-\frac{\lg \sigma}{\lg \sigma_{0}}\right),
$$

where $K$ is the axial swelling strain when the swelling stress $\sigma$ is $0.1 \mathrm{MPa}$.

The proposed constitutive model was compared with the Huder-Amberg model; it can be found that the expressions of the two models are similar. There is a linear relationship between swelling stress and swelling strain in equation (13), and the swelling strain shows a linear relationship with logarithm swelling stress in the Huder-Amberg model.

Some disadvantages of the Huder-Amberg model were found based on the analysis of equation (14). Variation of axial swelling strain varies with axial swelling stress when the maximum swelling stress $\sigma_{0}$ is larger than $10 \mathrm{MPa}$. For example, when the axial swelling stress $\sigma$ is larger than $1 \mathrm{MPa}, \lg \sigma$ is larger than 0 , the value of $1-\lg \sigma / \lg \sigma_{0}$ is less than 1. While, in the case of $\sigma$ less than $1 \mathrm{MPa}$, the value of $1-\lg \sigma / \lg \sigma_{0}$ is larger than 1 .

In the case of $0<\sigma<0.1 \mathrm{MPa}$ and $\sigma_{0}>1 \mathrm{MPa}$, the calculated axial swelling strain is larger than the value of $K$, which is not in accordance with the definition of $K$. It is difficult to describe the stress-strain relationship in the case of $\sigma \approx 0$. The calculated swelling strain will be infinite if swelling stress is approximately $0 \mathrm{MPa}$, which is not consistent with the results of swelling test. The Huder-Amberg model is shown to be an inappropriate constitutive model to describe the swelling stress-strain relationship in the case of $0<\sigma<0.1 \mathrm{MPa}$. The analyzed disadvantages of the Huder-Amberg model did not exist in the proposed model (equation (13)).

The constitutive model (equation (13)) was proposed depending on the relationship between virtual swelling stress and swelling strain shown in equation (3) and the relationship between virtual swelling strain and swelling stress shown in equation (4). A linear assumption was introduced in equation (3) and equation (4), which leads to a linear relation between swelling strain and swelling stress. Different types of swelling rock show different swelling stressstrain relationships; a linear stress-strain relationship will not be suitable for all types of swelling rock. In order to optimize the proposed constitutive model, additional swelling tests and research need to be conducted.

\section{Conclusions}

Swelling strain and swelling stress are the main test results to evaluate the characteristics of swelling rock. In order to study the properties of swelling rock, the swelling strain test and swelling stress tests were performed on gypsum rock samples drilled from a tunnel jobsite in Shanxi province, China. The study on the swelling constitutive model is an important issue for swelling rock. Based on the experimental data of swelling stress tests, a constitutive law describing the relationship between swelling strain and swelling stress was proposed by introducing the virtual swelling strain and 
virtual swelling stress. As a result of this study, the following conclusions were derived:

(1) The measured maximum swelling strain of gypsum rock sample in the swelling strain test was $4.397 \%$. Three stages of the swelling strain of gypsum rock were defined by the tests results, namely, rapid swelling stage, slow swelling stage, and steady stage. The slow swelling stage lasted for about 115 minutes in which the swelling strain accounted for $76 \%$ of the total swelling strain.

(2) The measured maximum swelling stress of gypsum rock was $3340 \mathrm{kPa}$. There was a negative linear relationship between swelling stress and swelling strain for the gypsum rock tested in the present research.

(3) The constitutive model was verified using the experimental data from the present research and the collected data from other literatures. The proposed constitutive model performs well in describing the variation of swelling strain with swelling stress for different types of swelling rock. The developed model has good agreements with test data in the condition of maximum swelling stress and maximum swelling strain.

In order to optimize the proposed constitutive model, additional swelling tests and research needs would be further conducted.

\section{Data Availability}

The data used to support the findings of this study are available from the corresponding author upon request.

\section{Conflicts of Interest}

The authors declare that they have no conflicts of interest regarding the publication of this paper.

\section{Acknowledgments}

This work was financially supported by the Special Science and Technology Innovation fund of Research Institute of Highway Ministry of Transport (Grant no. 2019-C505), the Central Public-Interest Scientific Institution Basal Research Fund (Grant no. 2020-9032), and the Science and Technology Project of Department of Transportation of Shanxi Province (Grant no. 2017-1-6).

\section{References}

[1] M. Lei, L. Peng, C. Shi, and S. Wang, "Experimental study on the damage mechanism of tunnel structure suffering from sulfate attack," Tunnelling and Underground Space Technology, vol. 36, pp. 5-13, 2013.

[2] D. Parsapour and A. Fahimifar, "Prediction of swelling rocks strain in tunneling," Geotectonics, vol. 50, no. 3, pp. 336-346, 2016.

[3] C. Butscher, T. Mutschler, and P. Blum, "Swelling of claysulfate rocks: a review of processes and controls," Rock
Mechanics and Rock Engineering, vol. 49, no. 4, pp. 1533-1549, 2016.

[4] H. H. Einstein, "Tunnelling in difficult ground? swelling behaviour and identification of swelling rocks," Rock Mechanics and Rock Engineering, vol. 29, no. 3, pp. 113-124, 1996.

[5] A. A. Jeschke, K. Vosbeck, and W. Dreybrodt, "Surface controlled dissolution rates of gypsum in aqueous solutions exhibit nonlinear dissolution kinetics," Geochimica et Cosmochimica Acta, vol. 65, no. 1, pp. 27-34, 2001.

[6] X. Ou, Y. Tang, Z. Zhong, and J. Su, "Test research on expansive force under small deformation of remolded expansive rock and soil," Chinese Journal of Rock Mechanics and Engineering, vol. 32, no. 5, pp. 1067-1072, 2013.

[7] M. R. Vergara and T. Triantafyllidis, "Influence of water content on the mechanical properties of an argillaceous swelling rock," Rock Mechanics and Rock Engineering, vol. 49, no. 7, pp. 2555-2568, 2016.

[8] S. Zhang, X. Leng, Q. Sheng, B. Li, and Y. Zhou, "Swelling and shrinkage characteristics study of lushi expansive rock under dry and wet circulation," Rock and Soil Mechanics, vol. 40, no. 11, pp. 4279-4288, 2019.

[9] Z. C. Tang, Q. Z. Zhang, and J. Peng, "Effect of thermal treatment on the basic friction angle of rock joint," Rock Mechanics and Rock Engineering, vol. 53, no. 4, pp. 1973-1990, 2020.

[10] M. E. Bilir, D. Sari, Y. V. Muftuoglu, L. D. Suits, and T. C. Sheahan, "A computer-controlled triaxial test apparatus for measuring swelling characteristics of reconstituted claybearing rock," Geotechnical Testing Journal, vol. 31, no. 4, pp. 279-284, Article ID 100755, 2008.

[11] J. D. Liu, Q.-Y. Li, and B.-W. Gong, "Swelling properties of expansive rock in middle route project of south-to-north water diversion," Chinese Journal of Geotechnical Engineering, vol. 33, no. 5, pp. 826-830, 2011.

[12] K. Wang and X. Diao, "Secondary development study of swelling rock humidity stress field constitutive model," Chinese Journal of Rock Mechanics and Engineering, vol. 34, no. 2, pp. 3781-3792, 2015.

[13] Z. C. Tang and Y. Y. Jiao, "Choosing appropriate appraisal to describe peak spatial features of rock joint profiles," International Journal of Geomechanics, vol. 20, no. 4, Article ID 04020021, 2020.

[14] W. Chang, W. Gao, X. Tang, Z. Zhang, and Z. Zhang, "Experimental study of swelling constitutive model of red sandstone," Journal of Hunan University of Arts and Science, vol. 31, no. 3, pp. 71-76, 2019.

[15] G. Anagnostou, "A model for swelling rock in tunnelling," Rock Mechanics and Rock Engineering, vol. 26, no. 4, pp. 307-331, 1993.

[16] X.-L. Liu, S.-J. Wang, E.-Z. Wang, and Q. Xue, "Study on time-dependent swelling constitute relation of swelling rock," Shuili Xuebao, vol. 37, no. 2, pp. 195-199, 2006.

[17] J. Zou, Y.-Y. Jiao, Z. Tang, Y. Ji, C. Yan, and J. Wang, "Effect of mechanical heterogeneity on hydraulic fracture propagation in unconventional gas reservoirs," Computers and Geotechnics, vol. 125, Article ID 103652, 2020.

[18] M. E. Bilir, Y. D. Sarı, A. Özarslan, M. Geniş, and İ. Sel, "Determination of the relationship between uniaxial and triaxial swelling equations for clay bearing rocks," Bulletin of Engineering Geology and the Environment, vol. 72, no. 3-4, pp. 565-577, 2013.

[19] C. Butscher, P. Huggenberger, and E. Zechner, "Impact of tunneling on regional groundwater flow and implications for 
swelling of clay-sulfate rocks," Engineering Geology, vol. 117, no. 3-4, pp. 198-206, 2011.

[20] W. Steiner, P. K. Kaiser, and G. Spaun, "Role of brittle fracture on swelling behavior of weak rock tunnels: hypothesis and qualitative evidence," Geomechanics and Tunnelling, vol. 3, no. 5, pp. 583-596, 2011.

[21] Y.-M. Liu, H.-M. Yu, C. Wang, and C.-L. Wang, "Research on mechanism of damage of anhydrock in dolomite layer to tunnel structure," Rock and Soil Mechanics, vol. 32, no. 9, pp. 2704-2708, 2011.

[22] S. Ren, G.-L. Deng, J. Wu, and J. Chen, "Immersion tests on gypsum rocks using fresh water," Rock and Soil Mechanics, vol. 38, no. 4, pp. 943-950, 2017.

[23] J.-S. Wang, G. Wu, Z.-M. Zhao, L. Li, Q. Lian, and L. He, "Experimental study on factors influencing the expansive properties of disturbed swelling rock," Soil Mechanics and Foundation Engineering, vol. 57, no. 1, pp. 84-91, 2020.

[24] J. Liu and H. Zhang, "Water content influence on properties of red-layers in Guangzhou metro line, China," Advances in Materials Science and Engineering, vol. 2017, Article ID 4808909, 12 pages, 2017.

[25] J. Huder and G. Amberg, "Quellung in mergel, opalinuston und anhydrit (swelling in marl, opalinus clay and anhydrite)," Schweizer Bauzeitung, vol. 88, no. 43, pp. 975-980, 1970.

[26] H. Grob, "Schwelldruck im belechtunnel," in Proceedings of the Berichte, Internationales Symposium für Untertagebau, pp. 99-119, Luzern, Switzerland, September 1972.

[27] P. Wittke-Gattermann and M. Wittke, "Computation of strains and pressures for tunnels in swelling rocks," Tunnelling and Underground Space Technology, vol. 19, no. 4-5, pp. 422-423, 2004.

[28] H. Einstein, "Comments and recommendations on design and analysis procedures for structures in argillaceous swelling rock," International Journal of Rock Mechanics and Mining Sciences \& Geomechanics Abstracts, vol. 31, no. 5, pp. 535-546, 1994.

[29] X. Miao, A.-H. Lu, X. Mao, and D. Zhang, "Numerical simulation for roadways in swelling rock under coupling function of water and ground pressure," Journal of China University of Mining \& Technology, vol. 12, no. 2, pp. 120-125, 2002.

[30] F. Chen, J. Wu, S. Ren, X. Ouyang, L. Wang, and J. Fan, “The swelling tests of anhydrite based on the humidity stress field theory," Rock and Soil Mechanics, vol. 39, no. 8, pp. 2723-2731, 2018.

[31] J. Yu, G. Liu, Y. Cai, J. Zhou, S. Liu, and B. Tu, "Time-dependent deformation mechanism for swelling soft-rock tunnels in coal mines and its mathematical deduction," International Journal of Geomechanics, vol. 20, no. 3, Article ID 04019186, 2020.

[32] T. Y. Elkady, M. F. Abbas, and M. A. Shamrani, "Behavior of compacted expansive soil under multi-directional stress and deformation boundary conditions," Bulletin of Engineering Geology and the Environment, vol. 75, no. 4, pp. 1741-1759, 2016. 